\title{
0 rigor científico: princípios elementares extraídos de Aristóteles no interesse da teologia
}

\author{
Scientific rigor: elementary principles extracted \\ from Aristotle in the interest of Theology.
}

\begin{abstract}
Resumo
Contra a tendência moderna de considerar como ciência apenas o conhecimento empírico-formal, e esse matematizado o quanto possível, deslegitimando, assim, os outros saberes, em particular o teológico, levantam-se aqui várias declarações de Aristóteles, mostrando que o rigor científico não é unívoco, mas analógico: ele se determina em função da natureza do objeto a ser conhecido. Essa seria uma regra epistemológica tão elementar que seu desconhecimento é taxado por aquele filósofo de apaideusia, ou seja, falta de formação básica na esfera do saber em geral. Para o Estagirita, um pepaideuménos, ou seja, um espírito bem educado exige para cada matéria apenas aquele tipo de rigor que a ela se adeque, cuidando em particular para não impor a tudo o rigor demonstrativo e menos ainda o matemático. Isso vale especialmente para a ciência teológica, cuja matéria, por ser transcendente, pede um rigor sui generis, que não deixa, contudo, de esposar, com toda fidelidade possível, os contornos próprios daquela matéria.
\end{abstract}

Palavras-chave: Rigor. Epistemologia. Paideia. Método teológico.

\begin{abstract}
Against the modern tendency to considerate just the formal-empirical knowledge as Science, and this one mathematized as much as possible, here many declarations of Aristotle are raised in order to show that the scientific rigour is not univocal but analogic: it is determined according to the nature of the object to be known. This is a so elementary epistemological rule that not knowing it is understood by that philosopher as apaideusia, i.e., lack of basic education in the knowledge sphere in general. To the Stagirite, a pepaideuménos, i.e., a well educated spirit requires to every subject just the kind of rigour which is adequate to it, attempting not to impose whether the demonstrative or the mathematical rigour to the subject. It is specially truth for the theological Science, whose subject, by being transcendent, asks for a sui generis rigour which has to be so faithful as possible to it.
\end{abstract}

Keywords: Rigour. Epistemology. Paideia. Theological Method.

Artigo recebido em 28 de julho de 2015 e aprovado em 25 de setembro de 2015.

* Doutor em Teologia pela Universidade de Lovaina - Bélgica. Professor do Programa de Pós-graduação em Teologia da PUC-PR. País de Origem: Brasil. E mail: osmcwb@gmail.com

Horizonte, Belo Horizonte, v. 13, n. 39, p. 1559-1579, jul./set 2015 - ISSN 2175-5841 


\section{Introdução}

Recolhemos nesse ensaio algumas afirmações de Aristóteles relativas à metodologia geral do conhecimento científico, tiradas especialmente de escritos maiores como: Metafísica (2002), Ética a Nicômaco (1973), Analíticos posteriores (2005a) e Tópicos (2005b). Completaremos essas citações com outras, essas de Sto. Tomás, extraídas principalmente das duas Sumas: a Suma teológica (= ST) (2001) e a Suma contra os gentios (= SCG) (1979). Daremos aqui as referências a esses clássicos, como se costuma, no corpo mesmo deste texto.

O interesse teológico deste trabalho é duplo: primeiro, mostrar que, do estrito ponto de vista epistemológico, a teologia é e pode ser uma ciência tão séria ou rigorosa como qualquer outra ciência, inclusive a moderna; segundo, convocar a teologia a rigorizar seu discurso, não por qualquer exigência cultural externa, mas a partir de seu próprio objeto: o mistério de Deus revelado, que merece o melhor do ser racional que é o homem.

\section{0 axioma mais elementar da epistemologia}

Como princípio geral de discernimento epistemológico em relação à variada a área dos saberes, Aristóteles põe um axioma elementar, que formulou nestes termos: "É próprio do homem educado (pepaideuménou) exigir em cada matéria (génos) tanto rigor (akribés) quanto comporta a natureza daquela matéria” (Ét. Nic. I, 3, 1094 b 24-25).

Pepaideuménos: nessa palavra está presente o termo paideia, ideia própria dos gregos, significando educação, formação, instrução, enfim, cultura (JÄGER, 1979). Portanto, pepaideuménos pode ser traduzido por culto, educado, mas também por bem formado, bem instruído, adequadamente preparado; disciplinatus, afeito a uma disciplina teórica, traduz Tomás de Aquino (SCG I, 3). 
Sobre o pepaideuménos, repete Aristóteles em outro passo: "É coisa do homem bem educado (pepaideuménou) ser capaz de julgar, de modo pertinente, acerca da maneira correta ou incorreta pela qual se exprime aquele que fala" (Das partes dos animais I, 1, 639 a 1-12).

Quanto a tò akribés, significa literalmente “o (que é) rigoroso”, adjetivo com valor de substantivo. Quer, pois, dizer rigor, precisão, exatidão. Tomás de Aquino traduz por "certeza”, enquanto Boécio havia já traduzido por “crédito". ${ }^{1}$ Mas talvez certeza e crédito, assim como clareza e evidência, sejam mais efeitos do rigor que conceitos a ele correspondentes. Como veremos mais adiante, Aristóteles usa também acribologia, dicionarizado em português.

O fundamento ontológico dessa regra primeiríssima é o realismo, segundo o qual o ser preexiste ao saber. Por outras: a realidade existe antes do conhecimento e o determina. Nas palavras de S. Tomás: "O cognoscível é anterior à ciência e é sua medida.”2 Aristóteles já havia dito: "O objeto da ciência mede a ciência.”3

Como se pode ver, a epistemologia (a teoria do saber) se funda na metafísica (a teoria do ser). E não pode ser diferente, de vez que a metafísica é a "filosofia primeira”. É, pois, a coisa que dá a medida do pensamento. Como se vê, o axioma elementar da teoria do conhecimento se pauta pelo simples bom senso.

Entretanto, não foi nessa linha que se constituiu a cultura moderna

\footnotetext{
${ }^{1}$ TOMÁS DE AQUINO: “É próprio do homem formado nas disciplinas do saber buscar tanta certeza em cada gênero de coisas quanta comporta a natureza da coisa em questão" (Disciplinati enim est in tantum certitudinem inquirere secundum unumquodque genus, in quantum natura rei recipit): Sobre a Trindade de Boécio III, proêm., pról. Pouco antes, o Aquinate tinha reportado a tradução do próprio Boécio, o qual, depois de elogiar o Estagirita com as palavras: "como foi otimamente dito por Aristóteles no começo de sua Ética", prossegue: "É próprio da pessoa instruída dar a cada coisa o crédito adequado ao modo da mesma" (Eruditi hominis est ut unumquodque ipsum est, id est per modum congruum ipsi rei, ita de eo fidem capere tentare).

${ }^{2}$ Scibile est prius scientia et mensura ejus: ST I, q. 14, a. 8, obj. 3.

3 "O saber é medido pelo sabível" (Hê epistème metreîtai tô epistetô ): Met. X, 6, 1057 a 12. Mas Aristóteles faz observar que há também o inverso: depois de ser medida pelas coisas, a ciência pode, por sua vez, medir as coisas, o que daria certa razão a Protágoras, ao afirmar que "o homem é a medida de todas as coisas" e aos pitagóricos, para os quais os números eram a essência e a medida de tudo. E exemplifica: um homem cuja altura foi medida pode, depois, com sua altura, medir os outros: Met. X, 1, 1053 a 31 - b 3. Poderíamos resumir tudo isso dizendo: as coisas são mensura mensurans e a ciência é mensura mensurata.
} 
hegemônica, com seu primado do cogito. 4 Sem dúvida, ela deu origem à ciência moderna e à sua potência prática, assim como às liberdades individuais e aos direitos sociais. Mas ela também tem muito a ver com as tragédias que ensanguentaram o século XX e com o grave drama que pesa sobre a humanidade atual, ameaçada em sua sobrevivência pelas armas nucleares e a devastação ecológica.

\section{Apaideusia: a ignorância epistemológica}

A ignorância da regra elementar acima referida, mandando adequar o rigor ao objeto em estudo, é taxada por Aristóteles de apaideusia, isto é, falta de educação epistemológica, carência de formação intelectual básica. Quem não sabe discernir em cada questão os argumentos próprios da matéria e os que lhe são estranhos demonstra apaideusia (Ét. a Eudemo I, 1, 1217 a 6-8).

Eis um texto maior, em que o filósofo repisa no que se poderia chamar o princípio primeiríssimo do discernimento epistemológico, para extrair dele consequências importantes:

O que mais importa em cada questão é levar em conta o rigor próprio da matéria em questão, e um rigor exigido segundo a medida (methódô) própria da respectiva pesquisa. Evite-se, portanto, procurar em todas as coisas o mesmo rigor. Por exemplo, o carpinteiro e o geômetra buscam ambos o ângulo reto, mas não do mesmo modo. O primeiro o busca apenas de modo utilitário, isto é, em função de sua obra. Já o segundo o busca em sua essência, isto é, em suas propriedades, de vez que tem uma intenção puramente teórica: a de conhecer a verdade. É desse modo que é preciso proceder em todos os outros domínios, para que não suceda que o secundário sufoque o principal. É preciso, pois, cuidar para, em todas as questões, não buscar a causa de um modo igual. Às vezes, basta estabelecer bem o fato, mesmo quando se trata de buscar os princípios, pois o próprio fato, além de início (prôton), pode ser também princípio (arché).5 Entre os princípios, uns são aprendidos por indução, outros pela

\footnotetext{
${ }^{4}$ Daí também a ideia analógica, para não dizer equívoca, de "produção" de conhecimento, expressão em voga nos meios acadêmicos. Em verdade, conhecimento, mais que se "produz", se obtém como "fruto de uma íntima e prolongada copulação com a realidade", segundo expressão de Platão em sua Ep. VII, 341, c 9-10. O que efetivamente se "produz" são impressos, reais ou virtuais, que não passam de expressões gráficas dessa entidade toda espiritual que é o conhecimento.

${ }^{5}$ Prôton = início temporal; arché $=$ princípio de entendimento.
} 
sensação, outros por hábito e assim por diante. Precisa, pois, esforçar-se para perseguir cada tipo de princípio conforme sua natureza e empenharse em definir seu alcance próprio. Efetivamente, os princípios são decisivos em relação aos desenvolvimentos ulteriores. Todo o mundo admite que o princípio é mais que a metade da questão em seu conjunto, pois por meio dele tornam-se claras muitas das coisas que se estão estudando (Ét. Nic. I, 7, 1098 a 26 - b 8).

Aristóteles insiste na impertinência de buscar em todo e qualquer saber provas apodíticas, ou seja, demonstrativas (Anal. post. I, 3, 72 b 19-23). ${ }^{6}$ Há efetivamente coisas para as quais as demonstrações são totalmente improcedentes. Para ele, não dar-se conta disso é apaideusia, ou seja, apedeutismo, falta de cultura, ignorância; digamos, em bom português, burrice epistemológica. Adverte o filósofo: "É sinal de apaideusia não saber de quais coisas se deve buscar uma demonstração e de quais não se deve" (Met. IV, 4, 1006 a 5-7).

Retomando esse axioma geral, aplica-o ao caso do princípio de contradição. Diz que para esse último não há e nem pode haver demonstração pelo fato de que ele é pressuposto em qualquer demonstração. "É um erro (pathos) [...] buscar uma razão das coisas das quais não há razão, como no caso do princípio da demonstração" (Met. IV, 6, 1011 a 12-13). E, no fim dos Analíticos posteriores, dá a seguinte justificação: "O princípio da demonstração não é uma demonstração. Por conseguinte, o princípio do conhecimento científico não é o conhecimento científico, mas [...] a intuição (noûs). Daí que a intuição pode ser considerada princípio do princípio" (19, 100 b 13-16).

O filósofo repete:

É mostra de apaideusia não saber distinguir entre as coisas que se devem demonstrar e as que não se devem demonstrar. É assim que alguns sustentam por apaideusia que esse princípio (o da contradição) deve ser demonstrado. Ora, se se pudesse demonstrar tudo, proceder-se-ia ao infinito e não haveria mais qualquer demonstração (Met. IV, 4, 1006 a 69).

\footnotetext{
${ }^{6}$ Aristóteles usa a palavra ciência em dois sentidos: no sentido estrito de saber "científico" ou demonstrativo, acepção própria dele; e no sentido lato de qualquer tipo de saber, inclusive teológico.
} 
Mas não é somente a respeito ao princípio da não-contradição que é ocioso aduzir razões apodíticas. Há muitas verdades que são evidentes por si mesmas, portanto, certíssimas, dispensando qualquer demonstração, como, por exemplo, "se estamos despertos ou se estamos dormindo" (Met. IV, 6, 1011 a 7-8), ou se existimos realmente ou se estamos apenas sonhando.7 Tal é o "saber intuitivo", saber facial e direto, como o saber que confere todo tipo de visão, desde ver (sensivelmente) o sol, até ver (espiritualmente) a Deus, passando por ver (intuitiva ou intelectualmente) os primeiros princípios especulativos, assim como os éticos. Em todos esses casos, a verdade não é entendida nem crida, mas justamente vista, intuída, contemplada (cf. SCG IV, 1).

Igualmente, o que chamamos hoje "utilitarismo" foi qualificado por Aristóteles como coisa de ignorantes. Diz num escrito de juventude: "Buscar [...] em toda a ciência a utilidade é próprio de quem ignora completamente a diferença entre as coisas boas e as úteis." Quem faz isso é um sujeito incapaz de distinguir entre as coisas que são amadas por si mesmas (boas) e as coisas que são amadas por causa de outra coisa (úteis). E o jovem filósofo conclui com despeito: "Portanto, buscar utilidade ou vantagem em tudo é algo de totalmente ridículo" (Protrético, fr. 12, ap. REALE, 1993, p. 412). Observemos que a crítica do então discípulo de Platão não vai aqui contra o útil, mas à redução de tudo ao útil.

O filósofo volta sempre à regra básica do discernimento epistemológico, aplicando-a agora ao campo da ética:

É necessário sempre exigir que o discurso (logoi) seja apropriado à natureza da matéria tratada. Segue-se daí que, no que tange à ação (moral), como advertimos desde o começo, o discurso só pode ser aproximativo (typô), não rígido (akribôs). Efetivamente, na ação não há nada de fixo, como acontece também em relação à saúde (Ét. Nic. II, 2, 1104 a $1-4)$.

\footnotetext{
${ }^{7}$ Descartes não se teria mostrado porventura apedeuta, quando, cheio de angústia, submeteu à demonstração racional a própria existência?
} 
Ele faz notar que, justamente na esfera da ética, há grandes verdades para as quais é descabido dar razões. Começa dando a regra geral: "Não é necessário submeter a exame todo problema e toda tese, mas apenas aquele ou aquela que venha a suscitar dúvidas para alguém que precisa de argumentos” (Tóp. I, 105 a 24). E como ilustrações de verdades morais que dispensam justificação teórica, Aristóteles põe a honra a ser tributada aos pais e o culto devido à divindade. Eis o que diz a propósito, com um grão de ironia: "Tudo o que precisam os que duvidam se se deve ou não venerar os deuses ou amar os pais é de um bom corretivo" (Tóp. I, 105 a 5-6). Para ele, com ignorantes desse gênero é inútil argumentar. E continua, um pouco trocista: São como os que, por deficiência visual, "duvidam se a neve é ou não é branca"; esses não precisam de razões, mas de um bom oculista (Tóp. I, 105 a 7-8).

Portanto, para Aristóteles, o que um homem culto ou bem formado precisa fazer, antes de adentrar um estudo ou um debate, é examinar, o quanto possível, a natureza da questão em pauta, para ver, em seguida, que tipo de rigor argumentativo ele pode exigir em tal questão. Fazendo assim, estará colocando os termos da questão de modo correto já em seu nascedouro, de modo que a questão fique efetivamente bem equacionada, isto é, bem encaminhada.

De fato, como discutir ou estudar um tema sem saber precisamente do que se trata, ou seja, sem antes fazer um discernimento, pelo menos genérico, sobre sua natureza? Sem isso, fala-se no ar. Uma discussão ou um estudo, feitos sem saber ao certo sobre o que versam, ao menos de modo genérico, só produzem fumaça, não luz. Cai-se então naquela falácia primária que o filósofo chamou de ignoratio elenchi, isto é, ignorância do tema central ou incompreensão do tema em debate. Isso torna enviesada toda pesquisa, levando a conclusões inconsequentes. Ora, sem estar, desde o início, minimamente equacionado, um problema torna-se insolúvel.

Ignorar esse princípio elementar é de mostrar falta de educação epistemológica. Paradoxalmente, o cientificismo moderno incide nesse tipo de 
apaideusia na medida em que exige para tudo, sem exceção, "provas científicas". Para essa mentalidade, o que não puder ser "provado cientificamente" não existe na realidade, mas só na imaginação. Evidentemente, são a fé e a teologia as vítimas maiores dessa visão, a qual, além de preconceituosa, é, no fundo, ignorante, enquanto confunde sem cerimônia saberes de ordens diversas.

\section{0 rigor varia em função da matéria}

Portanto, é somente a partir da natureza de uma determinada matéria é que se pode estabelecer o tipo de rigor que aquela matéria demanda e então montar o método correspondente. Afirma Aristóteles: "Buscar ao mesmo tempo a ciência (epistême) e o método (trópon) da ciência é algo de absurdo (átopon), ainda que nenhuma dessas duas coisas seja fácil de apreender” (Met. II, 3, 995 a 14).

Efetivamente, primeiro precisamos nos esforçar por ver qual é mesmo o objeto do nosso estudo. É só em seguida que podemos ver como chegar até ele. Pois, como saber a direção de nossos passos, se não sabemos nosso destino? Portanto, é a partir de cada área do conhecimento e do rigor que ela demanda que se pode estabelecer o método adequado, ou seja, o caminho que dê acesso àquela área. Pois o que é o método senão o conjunto das etapas, procedimentos e recursos que se montam e se mobilizam a fim de se conhecer determinado setor da realidade? Método é como uma máquina para apreender coisas. E é essa máquina que encarna o rigor, que um determinado assunto postula.

Dependendo, portanto, do tema, há rigor e rigor. Há, pois, diversidade de rigor, e não só quanto ao grau (rigor maior ou menor), mas também quanto ao tipo (rigor matemático, rigor empírico-formal, rigor teológico e assim por diante). Como se nota, rigor é um conceito analógico. Por isso, exigir em relação a tudo, indiscriminadamente, só um tipo de rigor é fora de propósito. É, contudo, o que ocorre muitas vezes, como verifica o próprio Aristóteles, não sem antes observar 
que isso se dá por força do hábito, que condiciona fortemente o conhecimento humano. Eis suas palavras:

(1) Alguns só estão dispostos a escutar quem fala com rigor matemático.

(2) Outros, ao invés, só escutam quem fala através de exemplos.

(3) Outros ainda exigem que se aduza o testemunho dos poetas.

(4) Alguns reclamam rigor (akribôs) em tudo absolutamente.

(5) Já outros julgam o rigor molesto (Met. II, 3995 a 6-9).

A essa altura o Estagirita se detém na análise do senso de mal-estar que a busca de rigor suscita em certos espíritos. Faz, primeiro, uma descrição do que se poderia chamar "síndrome da náusea do rigor científico", para dar, em seguida, o diagnóstico.

(O mal-estar que alguns sentem em relação ao rigor provém) seja de sua incapacidade de compreender os nexos do raciocínio, seja de sua aversão pelas sutilezas. $\mathrm{O}$ rigor efetivamente tem algo que pode parecer sutileza (micrología). Por isso, alguns o consideram qualquer coisa de mesquinho (anelêutheron), e não só nos discursos, mas também nos negócios (Met. II, 3, 995, a 9-12).

Esclarecendo esse passo, tal como foi explicado por Sto. Tomás, em seus Comentários aos livros da Metafísica de Aristóteles (II, lição 5, 1-7), digamos que vários são os motivos pelos quais o pensamento de rigor é sentido por alguns como algo de incômodo: ou porque dá impressão de ser algo de complicado, abstruso, incompreensível; ou porque parece inutilmente minucioso, excessivamente sutil e preso a miudezas; ou ainda porque se mostra uma coisa tacanha, que constrange o espírito, algo, enfim, de servil (anelêuteron), indigno de um homem livre. Esse sentimento molesto que o rigor pode suscitar provém, seja de mentes pouco dotadas, curtas e fracas, seja de espíritos incultos, carentes de disciplina intelectual, seja ainda do relaxamento e preguiça mental.

Registrado esse desenvolvimento tomasiano, voltemos ao texto do autor da Metafísica, que assim conclui seus reparos epistemológicos: 
Seja como for, é necessário, antes de tudo, formar-se (pepaidêusthai) a respeito do método (pôs) que se deve aplicar em cada espécie de ciência. (...) O que mais importa é não exigir o rigor (akribologían) matemático em cada coisa, mas apenas naquelas coisas que não possuem matéria. Por isso, o método (trópos) matemático não convém à física, pois toda a natureza possui matéria (Met. II, 3, 995, a 13-16). ${ }^{8}$

\section{A desastrosa confusão dos códigos do saber}

Disso tudo se depreende que o maior estrago que causa o apedeutismo epistemológico é a interversão e mesmo a confusão dos códigos do saber. A ignorância do método que seja adequado a uma determinada área de saber leva ao contrassenso de aplicar, por exemplo, aos mistérios sobrenaturais - campo da teologia - o método empírico-formal, campo das ciências ditas naturais. Em verdade, o que se passa aí é uma extrapolação abusiva do campo epistemológicocientifico para o metafísico-filosófico.

Ora, isso seria como "navegar em terra", como se exprime Sto. Agostinho; ou como comprar pão numa alfaiataria, na comparação de Tolstoi; ou ainda é como medir o grau de amor de um apaixonado com um estetoscópio. "Elementar, meu caro Watson!" poderíamos dizer, dirigindo-nos aos "sumos-sacerdotes" da ciência contemporânea, como Dawkins, Hawking, Jay Gould, Sagan, Weinberg, E. O. Wilson e outros, na medida em que esgrimem os critérios da "ciência do mundo" para julgar da existência d'Aquele que excede o "mundo da ciência”, tal como é hoje entendido (GIBERSON; ARTIGAS, 2010).

Vimos, porém, que segundo o princípio mais elementar da epistemologia, o critério do rigor é sempre relativo: é relativo ao assunto a que se aplica. De fato, uma coisa é o rigor que se pode exigir em relação às entidades imateriais ou

\footnotetext{
${ }^{8}$ Contra o que diz Aristóteles no final da citação, é preciso reconhecer que a ciência moderna, especialmente a física, se constituiu e progrediu em base à aplicação maciça da matemática, obtendo com isso resultados espetaculares. Há, contudo, que acrescentar que isso não se deu, como mostrou à farta a fenomenologia, sem o sacrifício da dimensão qualitativa, portanto humana, da realidade física, favorecendo assim o uso da ciência para fins de destruição do homem e da natureza.
} 
puramente formais. É o caso da matemática, da lógica e da filosofia metafísica em geral, onde o rigor metodológico é apodítico.

Outra coisa é o rigor que se pode exigir acerca das realidades materiais, em que agem os determinismos da natureza física. É o caso das ciências empíricoformais, chamadas também "ciências exatas", tais a física, a química, a biologia. Aí o rigor metodológico articula razões probantes, sem excluir as demonstrativas, com provas empíricas.

Outra coisa ainda é o rigor que se pode exigir acerca das realidades relativas ao ser humano, nas quais está implicada a atuação da vontade livre, como nas chamadas "ciências humanas": história, antropologia cultural, sociologia, psicologia, pedagogia e outras. Aí o rigor metodológico tem um caráter basicamente hermenêutico, consistindo em interpretar, de modo mais saturado possível, as intenções do agente humano, embora operando no seio dos mais variados condicionamentos.

Por fim, outra coisa ainda é o rigor que se pode exigir em assuntos ligados à fantasia criadora do homem, como nas artes: poesia, música, pintura e outras. Aí há também rigor metodológico, mas rigor extremamente flexível, consistindo em moldar-se à matéria de natureza estética, segundo a inspiração pessoal do artista. Efetivamente, quem poderia negar a presença do rigor ou, talvez melhor, do vigor na grande arte do mundo?

\section{0 rigor próprio da teologia}

Um caso absolutamente à parte é o rigor próprio que comporta o tratamento dos assuntos divinos revelados ou os "mistérios da fé", onde atua a vontade libérrima, cheia de amor e sapientíssima de Deus. É o rigor próprio da teologia, como sacra doctrina. Tal rigor comporta certamente uma técnica metodológica, mas que é toda informada por um elemento místico: a experiência da fé. A teologia, 
por ser scientia Dei (2Co 10,5; Cl 1,10), subjetiva e objetivamente, só pode ser uma ciência sui generis, como declara Sto. Tomás (ST I, q. 1, a. 1 ad 2).9 Seu rigor, portanto, deve ser igualmente sui generis, por mais que sui generis soe hoje, aos ouvidos da mentalidade tecno-cientificista, como estranho, contrastante e mesmo bizarro. Ora, se o rigor teológico não consiste nem em equações nem em experimentos, não é por deficiência que isso ocorre, mas por excesso. É que a matéria própria da sagrada teologia é de natureza revelada. Trata-se, efetivamente, da fé, portanto, de um saber sobrenatural, que transcende a pura racionalidade criada. Daí a chamada de atenção de Sto. Tomás em seu opúsculo Sobre as razões dafé:

Quero, em primeiro lugar, te advertir de que, nas discussões contra os incrédulos sobre os artigos da fé, não deves te esforçar por provar a fé através de razões necessárias. Isso anularia a sublimidade da fé, cuja verdade supera toda mente criada, não só humana, mas também angélica, sendo, antes, crida por nós como revelada por Deus mesmo. (...) Mas assim como nossa fé não pode ser provada com razões necessárias, por exceder a mente humana, também não pode ser improbada com as mesmas razões (...). Portanto, a intenção do polemista cristão não é provar a fé, mas defendê-la (cap. 2).

Mas não é porque a fé não pode ser submetida a provas apodíticas e a comprovações empíricas que ela dispensa o vigor da racionalidade e careça, por isso, de rigor. Ela possui seu rigor próprio, que não é menor, ao contrário, que o de qualquer outra ciência, moderna ou não. ${ }^{10} \mathrm{O}$ rigor próprio do discurso teológico pode ser apreciado pelo modo como teologizam os grandes teólogos, máxime Tomás de Aquino, o único teólogo que um Concílio da Igreja, o Vaticano II, propôs como "mestre", precisamente para o momento dogmático-especulativo da

\footnotetext{
${ }^{9}$ Para o Doutor Angélico, a teologia difere em gênero (differt secundum genus) e não apenas em espécie, de qualquer outro saber, enquanto seu princípio epistemológico é sobrenatural e não natural: é a "luz da revelação divina", e não a "luz da razão natural" como é para todas as outras ciências.

${ }^{10}$ Atendo-nos apenas à prima quaestio da ST, que trata do método teológico, levantamos aqui a hipótese, sem poder desenvolvê-la, de que a teologia combina, sempre em chave analógica, os dois modelos de ciência: o antigo e o moderno. Ela é em parte uma e outra coisa. Com efeito, segundo sua estrutura de fundo, a teologia se aproxima do modelo antigo de ciência, o aristotélico ("saber apodítico" a partir de princípios evidentes por si mesmos), enquanto ela também discorre partindo de princípios indemonstráveis, os mistérios, que, a título de "artigos da fé", valem como "argumentos de autoridade" infalíveis, dos quais se deduzem luzes para tudo o mais. É o que mostra Sto. Tomás no artigo 2 da prima quaestio. Já em seu percurso discursivo interno, relativo ao esclarecimento dos mistérios, a teologia corresponde melhor ao modelo moderno de ciência ("saber dialético", baseado na força explicativa de hipóteses e modelos teóricos não falsificados), enquanto ela também argumenta preferencialmente em base a razões probantes, especificamente, de conveniência. É o que sustenta o Doutor Angélico no artigo 8 da mesma quaestio (cf. BOFF, 1998, p. 61-109).
} 
construção teológica (OT 16,3), assim como para a relação fé e razão em geral (GE 10,1), recomendação essa que se tornou regra no atual Código de Direito Canônico (c. 252, § 3). Ora, para dizer que o Aquinate fala sempre com propriedade, precisão, exatidão, em suma, com rigor, seu maior comentarista, o Cardeal Cajetano, afirma que ele "fala sempre formalmente".

O mesmo vale para os grandes Padres da Igreja. Impressiona constatar o zelo com que buscavam o rigor das fórmulas dogmáticas, não por elas, mas para proteger a verdade da fé, em sua sublimidade divina e em sua virtude salvífica. Por exemplo, durante a grande crise ariana, travaram as lutas mais encarniçadas em torno do que parecia ser apenas uma questão de letras. Assim, pela verdade cristológica, brigaram estrenuamente contra o "i" de homoioúsios (semelhante, parecido), a quem opunham o homooúsios (igual, consubstancial). Igualmente cerraram fileiras em favor do "n" duplo de génnetos (gerado, nascido), em oposição ao "n” simples génetos (feito, criado) de Ário. "Picuinhas”, diriam os relativistas de hoje, como achava, de resto, o imperador da época, o pragmático Constantino. Contudo, por trás daquelas simples letras o que estava em questão era a fé na divindade de Cristo, o articulus stantis vel cadentis Ecclesiae, o qual diz finalmente respeito ao que interessa de modo decisivo: nossa salvação.

Se, efetivamente, as coisas deste mundo, para serem conhecidas, pedem atenção e precisão, quanto mais as coisas de Deus. Com o pretexto de os mistérios não serem cientificamente demonstráveis e menos ainda matematizáveis, o teólogo não pode se eximir de tratá-los com a mais elevada rigorização discursiva. Dizia a esse propósito Simone Weil que, em teologia, "a inteligência (...) deve ser mais aguçada, mais penetrante, mais precisa, mais rigorosa e mais exigente do que para qualquer outra" ciência. Para ela, a teologia deve "buscar uma precisão mais do que matemática; deve ser algo mais preciso do que a ciência.”

Essa pensadora explica que já era assim para os gregos, os quais teriam inventado a geometria, com todo o seu rigor, justamente porque se aplicavam ao mistério do divino com uma atenção extrema. Assim a mística teria sido o útero no 
qual a geometria foi concebida e pelo qual foi gerada (WEIL, 1993, p. 144-145). De fato, para os pensadores gregos, ao Divino não serve um discurso qualquer, mas apenas aquele que seja ao máximo theoprépes, termo técnico pelo qual designavam o discurso "condigno de Deus”, “a Deus conveniente”, portanto, um discurso supremamente rigoroso (JÄGER, 2002, p. 70).

Acresce que, por força da natureza de seu próprio objeto: o Deus do amor salvador, a teologia não postula apenas o rigor do pensar, mas também o rigor do viver: ela exige conversão, fé, amor, em suma, santidade. Em nenhuma outra ciência o pensar de rigor é tão dependente de uma vida de rigor, de tal modo que a teologia nunca deixa de pôr em causa a biografia de quem a pratica (BOFF, 2015).

\section{Generalização indébita do modelo empírico-formal de ciência}

Tende-se, sobretudo hoje, a herarquizar as ciências de acordo com o mesmo critério de rigor, o quantitativo. Assim, as ciências formais exibiriam um "rigor estritíssimo"; as empírico-formais, um "rigor estrito"; as humanas, um "rigor lato" e as artísticas um "rigor latíssimo”. Mas subjaz aí um equívoco de base: usar um critério de rigor igual para ciências desiguais. Como adverte Aristóteles, é enviesado aplicar a todas as ciências o critério matemático de rigor. Este vai bem para os objetos quantificáveis, como são os fenômenos da natureza física, mas não para os fenômenos humanos no que têm de propriamente humano, como a liberdade e a criação.

Rigor não é só rigor matemático, e isso já na linguagem corrente, onde se pode falar em rigor legal, rigor disciplinar, rigor moral, rigor doutrinal, rigor ascético, rigor místico e assim por diante. Quanto à ciência, ao lado do rigor quantitativo, pode-se colocar o rigor qualitativo. Teríamos assim um rigor geométrico e um rigor fino ou elegante, para evocar a célebre distinção pascaliana (PASCAL, 2001, n. 511 e 512). O rigor geométrico foi comparado por Péguy com uma mala quadrada, que, em sua rigidez, obriga as coisas nela postas a se 
adaptarem à sua forma. Bem diferente é o rigor fino, que seria como um saco, que, por ser flexível, se amolda à forma das coisas que nele se colocam. O primeiro se contenta em traçar a estrutura das coisas, como faz a régua do geômetra, enquanto o segundo se adapta às sinuosidades das coisas, como faz a faca do açougueiro, que corta a carne na linha de suas articulações, de acordo com a comparação de Platão para o filósofo dialético. Ora, o rigor da teologia é como esse último: ele adere do modo mais estreito possível aos mistérios de Deus, seguindo escrupulosamente o contorno delicado e rico de seus nexos internos (nexus mysteriorum).

É, pois, um contrassenso palmar impor o rigor geométrico a todas as áreas de saber. Mas é o que sucede com frequência hoje, com resultados nefastos para toda a cultura. Com efeito, a partir daquele equívoco, as outras ciências que não as “exatas” são relegadas a um status inferior, e isso não só do ponto de vista epistemológico (seriam menos precisas), mas até mesmo do ponto de vista axiológico (seriam menos importantes). Comete-se aqui uma confusão lamentável entre rigor e valor. Quanto mais uma ciência é matematicamente precisa, mais é apreciada. E ao contrário: quanto mais uma ciência é rebelde aos testes quantitativos, menos séria é considerada.

Mas não é, por acaso, em tal confusão mental que consiste toda a ideologia tecnocrática de hoje, recentemente denunciada pelo papa Francisco, em sua encíclica Lodato si” (cap. III), como "raiz da crise ecológica”? O resultado mais ruinoso da ditadura do método lógico-matemático em relação às "ciências humanas" é desumanizar o homem, na medida em que desvela apenas seu lado mecânico, obliterando o principal, que é seu lado especificamente humano: o da inteligência e da liberdade. De fato, a última filha da ideologia tecno-científica, o "pós-humanismo", pretendendo "melhorar" o homem através das novas tecnologias (nanotecnologia, biotecnologia, informática e ciências cognitivas), acaba por dispensá-lo de sua liberdade e responsabilidade, preparando-o, desse modo, para uma servidão sem precedentes. 
Disso tudo emerge a importância, inclusive epistemológica, de se recuperar a ideia larga de rigor, enquanto definido em função da natureza do objeto em foco. Por conseguinte, uma ciência é tanto mais rigorosa quanto mais fielmente casa com seu objeto específico, seja ele formal, material, espiritual, imaginário ou o composto variado de tudo isso. O certo é que não existe um código científico que sirva de modelo para todos os outros. A tendência atual de considerar a física como a ciência-padrão não passa de uma variante do cientificismo moderno: o fisicalismo, já denunciado por Aristóteles. ${ }^{11}$ Contra tal ideologia, deve-se pleitear, em favor de cada saber, a competência exclusiva de estabelecer seu próprio objeto teórico e o código metodológico que lhe corresponde. Isso só pode se dar, não por força de injunções externas e nem de convenções arbitrárias, mas a partir das exigências objetivas do respectivo objeto.

Se é possível estabelecer uma hierarquia especificamente valorial entre as ciências, esta não se fará partir do critério de mensurabilidade, que só se aplica às ciências das coisas materiais, mas, sim, a partir da importância de seu objeto. É o que faz Aristóteles no VI livro da Metafísica. Aí, tomando justamente o objeto como critério de valor, concede a supremacia absoluta à teologia, mesmo se filosófica. Demonstra-o com o seguinte silogismo: a ciência soberana é a ciência que tem por objeto a realidade soberana; ora, a realidade soberana é Deus; logo, a teologia é a ciência soberana (Met. VI, 1, 1026 a 10-23). Portanto, o critério do objeto manda conferir precedência às "ciências humanas" sobre as "ciências naturais", e a estas sobre as "ciências formais": a matemática e a lógica, que não passam de ciências puramente instrumentais.

Digamos, enfim, que tudo o que é importante não se demonstra nem se calcula; e vice-versa: tudo o que pode ser demonstrado e calculado não é importante, de modo que se pode tirar esta máxima: "o que realmente conta não se conta”. Qualquer um tem certeza matemática de quanto ganha, mas do amor da

\footnotetext{
${ }^{11}$ Afirma, com efeito, o filósofo que "a física seria toda a filosofia só no caso em que o divino não existisse": Sobre as partes dos animais I, 1, 641 a 36. Mas, de vez que o divino existe (justificando assim também a existência do teólogo-filósofo, o qual, de resto, se situa "acima do físico [toû physikoû tis anôtérô], dado que a natureza física é tão-somente um gênero de ser"), "a física, embora seja certa sabedoria, nunca será a sabedoria primeira": Met. IV, 3, 1005 a 33 - b 1. Notemos, de passagem, que aqui está a expressão mais próxima da ideia de "metafísica" que foi o nome dado posteriormente àquela obra aristotélica.
} 
mulher, dos amigos ou ainda de Deus só pode ter certeza moral, mas isso não por deficiência, mas justamente porque essas coisas são grandes demais para caberem em equações e demonstrações, de tal forma que por elas pode-se mesmo dar a vida, não por números ou silogismos. O mesmo vale para o sentido da vida, questão que não depende da ciência (saber do imanente), mas da sabedoria (saber do transcendente). Até no seio do Povo de Deus encontra-se quem diga que "a existência de Deus é mais clara que a luz do sol". De fato, para quem crê realmente, as verdades da fé são mais certas do que quaisquer verdades “científicas”, porque, como explica Sto. Tomás, "as outras ciências tiram sua certeza da luz natural da razão humana, que pode errar, enquanto esta ciência tira a sua da luz da ciência divina, que não pode se enganar." Esta certeza sobrenatural é uma razões que o santo Doutor aduz para mostrar a superioridade da sacra scientia sobre qualquer outra (ST I, q. 1, a. 5, c).

\section{Dois níveis de cultura articulados}

Sem dúvida, uma vez estabelecido o rigor requerido por um assunto, assim como o método adequado ao mesmo, é preciso treinar-se nesse método até que ele se torne um hábito mental. É o segundo momento de uma formação epistemológica. Vimos que, na falta do discernimento prévio em relação ao rigor adequado a cada área de saber, cai-se em extrapolações metodológicas, especialmente na ditadura do pensamento "científico", identificado pela cultura convencional com as ciências empírico-formais, especialmente com a física e, mais na base ainda, com a matemática, tida, por alguns, como a soberana entre todas as ciências.

Sem embargo, ao pepaideuménos não compete apenas a formação numa disciplina específica. Ele ainda precisa se dotar de uma cultura geral ampla que lhe permita julgar acerca de tudo a partir dos princípios últimos, cultura essa que a tradição chamou "sabedoria" e que a distinguiu da "ciência", como saber dos 
valores penúltimos. Mas como hoje é a "cultura científica” que predomina, e esta é do particular, é preciso insistir na urgência de adquirir uma cultura do todo: a "cultura sapiencial".

E é isso que pleiteia Aristóteles. ${ }^{12}$ E o faz, mesmo ao tratar de epistemologia. De fato, depois de ter, mais uma vez, criticado a confusão de códigos de saber, dizendo que "é tão descabido pedir persuasões a um matemático quanto exigir demonstrações de um orador", prossegue: "Cada um julga bem daquilo que conhece e só disso é bom juiz. Portanto, em cada campo, julga de modo competente quem foi bem formado naquele campo (kath'ékaston ho pepaideuménos). E é bom juiz em geral quem tem uma preparação global (hó perí pân pepaideuménos)" (Ét. Nic. I, 3, 1094 b 26 - 1095 a 3).

Como se pode ver aí, o filósofo fala de uma cultura dupla: uma geral e outra especialística. Essa última se constrói depois, encima e dentro da primeira, que é a mais importante. Portanto, para ele, o pepaideuménos, ou seja, o homem verdadeiramente bem educado é quem possui, tanto uma cultura universal, como uma cultura particular. Em suma, ele precisa ser um espírito cultivado nos princípios e valores mais elevados em absoluto, e, ao mesmo tempo, um entendido nalguma arte ou técnica particular. Seria idealmente um sábio e um cientista.

Portanto, a boa educação, a educação completa se dá em dois planos formativos ou em duas paideias: uma paideia geral ou "sapiencial”, própria do homem culto ou sábio, e outra particular ou "prudencial”, própria do especialista ou perito. As duas são necessárias. Pois, pouco adianta ter uma cultura teórica geral, se não se tem uma cultura prática particular; mas adianta menos ainda saber o "como" das coisas, sem saber seu "por que".

Ora, numa cultura dominada pela tecno-ciência como a nossa, o que é mais necessário e urgente é a primeira paideia, aquela que nos mostra o sentido da vida,

\footnotetext{
${ }^{12}$ Para nosso filósofo, como, de resto, para toda a cultura antiga, incluindo a bíblica, a sabedoria é, sem contestação, o saber absolutamente culminante, pois é o saber do bem-viver à luz dos valores supremos. Entre os gregos, a sabedoria se confunde com a própria filosofia, já pelo nome. Para a proeminência da sabedoria sobre todos os outros saberes em Aristóteles, cf. todo o cap. 2 do livro I da Met. e todo o cap. 7 do livro VI da Ét. Nic.
} 
seu destino último. De fato, hoje, sobram cientistas e técnicos, e faltam sábios e homens de bem. Na política também, sobram governantes e gerentes, e faltam estadistas e servidores do bem comum. Ora, quando falta a paideia I, a paideia II toma o seu lugar. Instala-se então na sociedade o reino dos tecnocratas e, na cultura, o império dos cientistas e do cientificismo.

Mas, felizmente, constata-se, para usar a distinção da Escola de Frankfurt, que a crença mágica no poder da "razão instrumental" está recuando em favor da confiança na "razão substancial", aberta aos valores espirituais. Com a emergência da espiritualidade na cena do mundo, assiste-se ao crepúsculo do niilismo e anuncia-se a alvorada do sentido (BOFF, 2014, p. 503-521). Com isso, abre-se também um espaço maior para o reconhecimento cultural do saber teológico, ao mesmo tempo em que este recebe um estímulo particular para rigorizar ainda mais seu discurso.

\section{Conclusão}

Ao termo desse estudo, fica claro que "rigor" é um conceito analógico. Assim, embora caracterize todo saber científico, esse conceito não se aplica por igual a todas as ciências. Dado que estas têm objetos distintos, exigindo cada uma seu rigor próprio, o rigor também será sempre distinto. Que não se diga que essa é apenas a opinião de Aristóteles. Esse pensador, no ponto em questão, nada mais fez que expressar a ordem ou a estrutura objetiva do conhecimento racional, aduzindo para tanto razões tão límpidas que são quase autoevidentes.

Tal concepção analógica de rigor permite criticar o estreitamento nada científico, mas ideológico, a que a cultura moderna submeteu a ideia de ciência, aplicando-a prevalentemente às ciências empírico-formais, com a consequente desqualificação epistemológica das outras ciências, principalmente da teologia, 
sendo isso tanto mais chocante quanto é superior o objeto teórico dessas últimas em relação ao das primeiras.

A vantagem, para a teologia, da ideia de rigor, tal como foi tirada a limpo por Aristóteles, é dupla: primeiro, mostrar que o saber teológico pode perfeitamente reivindicar a categoria de ciência, por ser suscetível de um rigor próprio, rigor, de resto, sui generis, por ser sui generis seu objeto teórico: o Mistério revelado; segundo, provocar a teologia para que confira efetivamente a seu discurso o rigor que mais se aproxime do nível de seu objeto próprio, o qual, por ser ao mesmo tempo transcendente e interpelador, solicita ao extremo o ser humano tanto em sua potência racional, quanto em sua abertura existencial, como testemunharam os grandes Doutores da Igreja.

\section{REFERÊNCIAS}

ARISTÓTELES. Metafísica. Tradução e comentário de G. Reale. São Paulo: Loyola, 2002, V. 2.

ARISTÓTELES. Ética a Nicômaco. São Paulo: Abril Cultural, 1973. Col. Os pensadores, n. 4 .

ARISTÓTELES. Analíticos posteriores. In: ARISTÓTELES. Órganon. Tradução de E. Bini. Bauru (SP): Edipro, 2005a.

ARISTÓTELES. Tópicos. In: ARISTÓTELES. Órganon. Tradução de E. Bini. Bauru (SP): Edipro, 2005b.

BOFF, C. Teoria do método teológico, Petrópolis: Vozes, 1998.

BOFF, C. O livro do sentido: crise e busca de sentido hoje. São Paulo: Paulus, 2014, v. I: Parte crítico-analítica.

BOFF, C. Teologia e espiritualidade: por uma teologia que ilumine a mente e inflame o coração. Pistis et Práxis, Curitiba, v. 7, n. 1, p. 112-141, jan./abr. 2015.

GIBERSON, K.; ARTIGAS, M. Profeti senza Dio: anche la scienza ha i suoi sacerdoti. Cinisello Balsamo (MI): San Paolo, 2010.

JÄGER, W. Paideia: a formação do homem grego. São Paulo: Martins Fontes, 1979 (orig. Berlim, 1936). 
JÄGER, W. Cristianismo primitivo e paideia grega. Lisboa: Ed. 70, 2002.

PASCAL, B. Pensamentos. Edição, apresentação e notas de L. Lafuma. São Paulo: Martins Fontes, 2001.

REALE, G. História da filosofia antiga. São Paulo: Loyola, 1993, v. I.

TOMÁS DE AQUINO. Suma teológica. Ed. bilíngue latim e português. São Paulo: Loyola, 2001, v. I.

TOMÁS DE AQUINO. Súmula contra os gentios. Tradução de L. J. Baraúna. São Paulo: Abril Cultural, 1979. Col. Os Pensadores.

WEIL, S. A gravidade e a graça. São Paulo: Martins Fontes, 1993. 